\title{
"Medical treatments are also part of God's gift": Holy water attendants' perspectives on a collaboration between spiritual and psychiatric treatment for mental illness in Ethiopia
}

Laura Asher $^{1+*}$, Ribka Birhanu'² + , Yonas Baheretibeb ${ }^{2}$, Abebaw Fekadu 2,3,4

tJoint first authors

${ }^{*}$ Corresponding author

${ }^{1}$ University of Nottingham, Division of Epidemiology and Public Health, Nottingham, UK

${ }^{2}$ Addis Ababa University, College of Health Sciences, Department of Psychiatry, Addis Ababa, Ethiopia

${ }^{3}$ Addis Ababa University, College of Health Sciences, Centre for Innovative Drug Development and Therapeutic Trials for Africa (CDT-Africa), Addis Ababa, Ethiopia

${ }^{4}$ Brighton and Sussex Medical School, Global Health \& Infection Department, Brighton, UK

\section{Ethical considerations}

Ethical approval was granted by the Department of Psychiatry, College of Health Sciences, AAU. Written informed consent was obtained from all participants. 


\section{Abstract}

\section{Introduction}

3 In Ethiopia, traditional and spiritual treatments, such as holy water, are used by people with

4 mental disorders instead of, or alongside, psychiatric services. Collaborations between

5 traditional and psychiatric providers may increase access to evidence-based treatments and

6 address human rights abuses. This study aimed to explore the perspectives of holy water

7 attendants on a novel collaboration between holy water and psychiatric care, at St Mary's

8 Clinic, Entoto, Ethiopia and to characterize the users of this service.

\section{Methods}

10 Semi-structured interviews were conducted with 14 holy water attendants, who run group

11 houses for holy water residents and are paid by family members. A thematic analysis was

12 conducted. Socio-demographic and clinical data were extracted from the records of all patients

13 who had attended the clinic.

\section{Results}

15 A total of 174 individuals have attended the clinic in the three years since it opened. The majority 16 were diagnosed with schizophrenia. Holy water attendants provide a partial gatekeeping role to 17 psychiatric care, selecting which of their clients they think will benefit and, for these individuals, 18 facilitating attendance to the clinic and anti-psychotic medication adherence. Psychiatric care 19 was felt to be compatible with holy water by some, but not all, attendants. However, family 20 members often had the 'final say' in individuals attending the clinic, in some cases putting up 21 strong resistance to using psychiatric care.

\section{Conclusion}

23 A novel collaboration is acceptable to some holy water attendants and may increase access to 24 psychiatric care amongst people with mental illness living at a holy water site in Ethiopia. 


\section{Introduction}

3 There have long been calls for collaboration between traditional and biomedical care providers

4 in the delivery of physical and mental healthcare in low and middle income countries (LMICs).

5 In settings with few specialists, all available resources, including non-specialists and traditional

6 practitioners, should be harnessed to increase access to healthcare (Gureje et al., 2015).

7 Informal links between religious healers and psychiatrists are not new to Ethiopia. In their 1968

8 ethnographic study of the Ghion holy water site, Giel et al. remarked "[the holy water priest]

9 sends some of his cases to the nearby health centre, and there is a two-way trickle of patients

10 between his place and Emanual Mental Hospital in Addis Ababa" (Giel et al., 1968). The

11 Ethiopian government has recognized the potential role of traditional practitioners in mental

12 health services (National Mental Health Strategy 2012-2015, 2012), but there are few examples

13 of formal collaborations in practice (Kassaye et al., 2006).

14 In Ethiopia, health is traditionally understood as a, "state of equilibrium among the

15 physiological, spiritual, cosmological, ecological and social forces associated with a person"

16 (Vecchiato, 1993). Across Christian, Muslim and animistic faiths, explanatory models for mental

17 illness in Ethiopia have traditionally focused on the supernatural, grouped into: (1) possession

18 by evil spirits, resulting from behaviours such as walking alone in the woods; (2) punishment by normally benevolent guardian spirits (e.g. Wuqabi, Zar) for sins or broken taboos (for example, entering a long-closed room without blessing oneself) and (3) bewitchment or curses cast by individuals thought to possess powers, including Kallicha (Muslim) and Debtera (Christian) (Giel et al., 1968; Kahana, 1985; Kortmann, 1987; Mercier, 1997; Mulatu, 1999; Teferra \& Shibre,

23 2012; Torrey, 1967). More recent accounts include psychosocial causes such as stress, poverty, 24 and substance abuse (alcohol and khat) (Girma et al., 2013; Mulatu, 1999; Teferra \& Shibre, 25 2012). A system of phenomenological classification exists in Ethiopia, which includes an illness 26 that is conceptually equivalent to psychosis (Kortmann, 1987), typically described in terms of

27 behavioural features, for example, disorganized speech or disrobing, rather than thought 28 disorders (Alem et al., 1999; Shibre et al., 2010). 
1 In Ethiopia access to evidence-based mental healthcare is limited to Amanuel Mental

2 Specialized Hospital in Addis Ababa and a small number of outpatient clinics. Whilst mental

3 health is being integrated in primary care in several pilot sites across Ethiopia (Fekadu et al.,

4 2015), in rural settings, only 58\% of people with psychosis report lifetime access to psychiatric

5 care (Fekadu et al., 2019). In Addis Ababa, only 10\% of street homeless with psychosis have

6 ever accessed treatment (Fekadu et al., 2014). Family members are typically the main care

7 providers for people with mental illness (Asher et al., 2017), whilst support from the community

8 or non-governmental organisations (NGOs) is negligible (Fekadu et al., 2019). Traditional and

9 religious healing is commonly sought; lifetime usage is $85 \%$ amongst people with psychosis

10 (Fekadu et al., 2019). Around half of individuals who ultimately seek psychiatric care for mental

11 disorders have previously attended traditional or religious healers (Bekele et al., 2009).

12 Holy water (tsebel) is believed to have curative properties; it is the most commonly used type of

13 traditional or religious healing for mental illness (Bekele et al., 2009). Holy water is also

14 commonly used to address physical illness or even minor social difficulties. Most Orthodox

15 Christian churches have a holy water source attached, but some are particularly popular as

16 healing sites. Holy water is free to use and accessible to anyone. For most attendees, the

17 process is short and may involve splashing, bathing or drinking the water, and attending prayers

18 led by holy water priests (Giel et al., 1968; Mercier, 1997). Those with more severe complaints,

19 most commonly chronic mental illness, may reside nearby for months or years to use the

20 facilities. These individuals are either accompanied by family members or holy water attendants

21 (astamami). A range of other healers exist in Ethiopia, including Debtera, Kalicha and Tanqway,

22 who to treat spirit possession through exorcism and rituals (Selamu et al., 2015).

23 There are several rationale for collaboration between traditional and psychiatric care providers,

24 including first, to aid the early detection and treatment of mental illness, which may improve

25 outcomes (Patel, 2015). Second, to minimise harmful practices, such as neglecting, restraining

26 or physically abusing patients. A survey of 693 traditional and faith providers found that

27 amongst people receiving care for mental illness, physical restraint was used in $4 \%$ cases in

28 Kenya, 21\% in Ghana and 63\% in Nigeria (Esan et al., 2019). Third, to raise awareness amongst 
1 psychiatric practitioners of the spiritual needs of people with mental disorders (Mulatu, 1999).

2 And fourth, to capitalize on the powerful influence of traditional practitioners to reduce stigma

3 and encourage community support for people with mental illness (Selamu et al., 2015).

4 Potential tasks for traditional practitioners include detection and treatment of mental health

5 problems, including monitoring of relapse, medication adherence and side effects, and referral

6 to primary or secondary care (Gureje et al., 2015). Proposed models of collaboration include (i)

7 task-shifting, whereby psychiatric treatments, for example psychotropic medication, are

8 delivered by traditional healers, (ii) a collaborative model, whereby practitioners refer to each

9 other or assess complex cases together (Campbell-Hall et al., 2010) and (iii) a fully integrated

10 approach, where individuals are routinely offered both traditional and psychiatric treatments

11 within the same consultation. In several African countries, traditional healers, clergymen and

12 psychiatric care providers report being open to collaboration and recognize the benefits of

13 receiving both types of care (Campbell-Hall et al., 2010; James et al., 2014; Musyimi et al., 2016;

14 Solera-Deuchar et al., 2020). However other reports suggest that mutual distrust between

15 traditional and psychiatric providers, stemming from skepticism of treatment efficacy and

16 human rights concerns, may be a key barrier to collaboration (Green \& Colucci, 2020; van der

17 Watt et al., 2017). Despite being widely advocated, there are few descriptions of how

18 collaborations have been established in practice, let alone how they are viewed or their

19 components accessed (Read, 2019)(Gureje et al., 2015). Furthermore, little is known about the

20 socio-economic or clinical profile of people who use collaborative treatment services.

\section{Study context}

22 Holy water site (spiritual care)

23 The study is set in Entoto, an elevated area on the northern perimeter of Addis Ababa, capital

24 city of Ethiopia. There are two Orthodox Christian churches at Entoto, St. Mary's and St

25 Michael's (see Fig. 1). Both churches have popular holy water sites within 30 minutes walk. The

26 sites consists of several prayer compounds and separate buildings with piped holy water

27 available at points around the walls. Ceremonies, involving prayer, baptism and the ordering of

28 attendees to drink holy water, are conducted daily by the holy water priests. It is estimated that 
at any given time approximately 250 and 500-700 people live around St Mary's and St Michael's

2 holy water sites respectively, mainly in basic dormitory-style houses run by holy water

3 attendants. Attendants undertake the role to generate personal income; they have no religious

4 or healthcare training. They are paid by family members to support residents' attendance at

5 holy water ceremonies, bathing and eating.

$7 \quad$ Psychiatric care

8 In December 2011 the Mental Health Society of Ethiopia began a psychiatric outpatient service 9 at a primary care clinic at Entoto in collaboration with the Department of Psychiatry at Addis 10 Ababa University (AAU) and with the approval of priests from St Mary's church. The Mental

11 Health Society is an NGO that was founded by family members of people with mental illness

12 and psychiatrists. The aims of the organization are to advocate for people with mental illness

13 and to provide community-based mental health services. It is funded by donations from

14 individuals, hospitals, universities and banks.

St Mary's Clinic, which now runs once a fortnight, was set up primarily to provide mental health care to the residents of the holy water site, however any person in need of mental health care

17 can access the clinic. Psychiatry residents from AAU conduct a full psychiatric evaluation,

18 prescribe appropriate medication, including anti-psychotics, mood stabilizers and antidepressants and provide psychoeducation. There are no other psychosocial interventions, nor

20 any treatment for substance use disorder, available at St Mary's clinic. The clinic is coordinated

21 and funded by the Mental Health Society of Ethiopia and all medications are provided free of

22 charge. Patients can be referred to outpatient clinics in central Addis Ababa or inpatient

23 services at Amanuel Hospital, where alcohol detox and limited psychosocial treatments are

24 available; however in practice such referrals are uncommon.

Collaboration between spiritual and psychiatric care

26 In 2011 psychiatrists from AAU met with high-level clergymen from the Ethiopian Orthodox

27 Church to raise awareness of the needs of people with mental illness and to negotiate for a 
1 collaborative approach. With the agreement of church leaders, psychiatrists made field visits to

2 Entoto to observe the holy water rituals and identify the needs of holy water users. Stigma,

3 physical and verbal abuse towards holy water users and physical restraint by the attendants

4 was observed. Consultative meetings were subsequently held between psychiatrists and St.

5 Mary's Church priests. Despite disagreement relating to explanatory models for mental illness,

6 an agreement was made to collaborate as there was universal recognition of the unmet needs

7 of some holy water users. A training manual was developed for holy water priests and

8 attendants adapted from a manual for support workers of homeless people with mental illness

9 in Addis Ababa (Fekadu et al., 2014). Holy water priests and attendants attended workshops

10 covering the nature of mental disorders, clinic services, stigma and discrimination, and how to

11 respond appropriately and safely to aggressive behaviour. The collaboration was publicised in

12 print media and local radio. Holy water attendants typically accompany patients to the clinic,

13 but there is no structured referral system. Use of the clinic, including patient flow and

14 characteristics of service users, has not been systematically assessed previously.

\section{Study aim}

17 The primary aim of this study was to explore the role of holy water attendants and their

18 perspectives on a collaboration between holy water and psychiatric care in Ethiopia. To

19 contextualize these findings, a secondary aim was to characterize the users of this service. This

20 information is needed to guide services to best meet the needs of current and potential users.

\section{Methods}




\section{Study design}

2 A mixed methods study was carried out. The main component was a qualitative study of the holy water attendants' role and attitudes towards St. Mary's clinic. In addition, we conducted a descriptive evaluation of numbers and characteristics of patients attending the clinic.

\section{Qualitative study}

8 Data collection

9 To gather information on the site layout and activities and the holy water attendants' role, XX conducted three visits to St Mary's and St Michael's holy water sites and held meetings with members of the St Mary's church clergy, the holy water attendants' union leader and the Mental

12 Health Society coordinator. Semi-structured interviews were conducted with 14 holy water 13 attendants in September and October 2014. Attendants were sampled purposively to ensure 14 balance for (i) base at St. Mary's and St. Michael's sites, (ii) previous attendance and nonattendance to clinic, (iii) those bringing new and follow-up patients and (iv) gender. It was anticipated that some attendants would have attended the AAU training, but this was not an

17 inclusion criteria. The study focused on attendants as it was hypothesised this group would 18 influence clinic attendance.

Holy water attendants were identified when they attended the clinic with patients or through

22 stages. First, by asking attendants who had attended the clinic to suggest colleagues who did not

23 typically attend. Second, by asking these attendants to suggest others who also did not bring 24 clients to the clinic. Participants were approached by telephone or face to face. One potential 25 participant declined due to having insufficient time. Interviews were structured using a topic 26 guide, which covered the attendants' role, attitudes towards the clinic and decision-making 27 around bringing patients. The topic guide was translated into Amharic prior to use. The interviews 28 lasted a mean of 35 minutes. The interviews were conducted in Amharic by XX, a female 29 psychiatry resident with training in qualitative research methods. Interviews were audio 
recorded with supplementary hand-written notes. Interviews were conducted in a private room at the clinic. $X X$ and $X X$ discussed initial impressions and made minor amendments to the topic guide as the study progressed. Transcription and translation to English of the recorded material was carried out.

Data analysis

7 A thematic analysis was conducted. Thematic analysis is a method which can draw on both a realist approach (involving the description of experiences) and a constructionist approach

9 (involving consideration of how those experiences reflect wider societal discourses)(Braun \& Clarke, 2006). An inductive (data driven) approach to identifying themes was employed; we did

11 not consider the data with an a priori coding frame. Four of the transcripts were first

12 independently coded by two investigators ( XX and XX). Differences in the coding framework were discussed and a final coding framework was agreed. The remaining transcripts were then coded manually by XX using the agreed coding framework, adding additional codes as required by the data. XX collated the codes into potential themes, by seeking repeated patterns of meaning across the dataset (Braun \& Clarke, 2006). Differences in experiences and views between participant types were noted, for example between those who had and had not attended the clinic. XX created a thematic framework, which was discussed and agreed with XX. Finally, XX reread a selection of the full transcripts to confirm that the final thematic framework adequately reflected the data collected. Quotes were selected by XX and XX to exemplify each theme.

\section{Description of outpatient clinic attenders}

22 We conducted a secondary data analysis of routine medical records at St Mary's Clinic. These records were originally completed by psychiatry residents for all clinic attenders. At first clinic attendance psychiatry residents record a diagnosis, using DSM-IV criteria, based on the history and mental state examination. At subsequent clinic attendances psychiatry residents ascertain whether there has been clinical improvement, by comparing current symptoms, self-care and risk

27 assessment, against the previous assessment. The medical records of all patients who had 28 attended the clinic since it opened were reviewed by $\mathrm{XX}$, covering the period from December 2011 to July 2014. Socio-demographic and clinical data (including diagnosis and treatment) were 
extracted from patient records and recorded on a data extraction sheet. 'Clinical improvement' was determined by the subjective assessment of the clinician, where this was documented in the notes. We anticipated that not all holy water site residents would attend the clinic, but that the majority of clinic attenders would be holy water site residents. A simple descriptive analysis was

\section{Results}

\section{Description of clinic attenders}

14 One hundred and seventy four patients attended the clinic between December 2011 and July

15 2014. The mean number of patients per clinic session increased from seven in 2012 to 25 in 2014

16 (Table 1). There were large amounts of missing data for socio-demographic and clinical variables.

17 Patients were mainly men (79.3\%) and the majority were 20 -39 years (76.5\%) (Table 2 ). Over half came from Addis Ababa and nearly $90 \%$ were educated. The majority were Orthodox Christian (87.9\%), with minorities of Protestant Christian and Muslim attenders. Most patients attended St. Michael's holy water site (86.9\%), with only $13.1 \%$ from St. Mary's site. Around two thirds of patients were accompanied to the clinic by the holy water attendants, $27.6 \%$ were accompanied by family and $6.9 \%$ were accompanied by both. Only four patients were not living at the holy water site. Amongst those living at the site, $48 \%$ stayed for less than one year, $25 \%$ stayed between one and five years, and $18.1 \%$ stayed for more than five years (see Table 3 ).

The most common diagnosis was schizophrenia (73.3\%), whilst a minority had bipolar disorder,

27 substance use disorder or major depressive disorder (Table 4). Nearly half had previously received treatment at Amanuel Mental Specialized Hospital. Since first coming to the clinic, most 
1 were seen four or more times (78.8\%). Around three quarters had experienced some clinical

2 improvement whilst attending the clinic.

\section{Qualitative findings}

4 Thirteen male attendants and one female attendant (the only female attendant at either site)

5 were interviewed. St. Michael's and St Mary's holy water sites were equally represented. Nine of

6 the included attendants had ever brought patients to clinic whilst five had not. Of those that had

7 brought patients to the clinic two of them were attending for the first time. Nine had previously

8 attended the AAU training.

9 Four main themes were identified: the role of holy water attendants, attitudes towards

10 psychiatric treatment, decisions about use of psychiatric treatment and potential service

11 improvements

\section{Theme 1: Role of holy water attendants}

\section{Experience and workload}

14 The majority of the attendants had originally come to the holy water site for treatment of their

15 own physical or mental illness, and had later taken on their current role. For some participants 16 their illness experiences led them to treat their patients with empathy.

"For four years, I was leading a painful life. I went to different hospitals and health centres then I came here and I recovered. That is why I take care of the patients just like I would myself" (A12, clinic non-attender)

Attendants reported supporting between five and ten patients. An attendants' union reportedly ensures the patients are being fed, cleaned and are not subject to physical or sexual violence. However it was not clear how this was enforced. Attendants reported that patients' families typically visit once a month to pay the attendant and supply money for their relative's food. Some

25 attendants described supporting destitute patients without charge. According to attendants, their services include the following components. 


\section{Support to meet daily needs}

Attendants described taking patients to the nearby river weekly to maintain personal hygiene and wash clothes, and buying and preparing their food. Inadequate food supply was usually due to the family having insufficient means or because the family reportedly wished to punish the patients for using alcohol or khat. In some cases food intake was restricted due to fasting practices that are traditional at holy water sites.

"If the family can afford it then they will also pay for breakfast. It depends on the family, since the majority of the patients come for addictions the family do not want them to be comfortable" (A10, clinic attender)

\section{Support to attend holy water rituals}

Attendants reported accompanying patients to the baptism area and church on a daily basis. Priests were not involved in the daily activities of the patients or attendants, nor in discussions about the patients' treatment or progress.

"We don't discuss about patient's treatment [with the priests]. [The priests] are doing their church service only. We go to the church service, let the patients be baptized, attend ritual congregation and hear their preaching. Beyond this we do not have much interaction" (A9, clinic attender)

\section{Restraining patients}

The attendants expressed a sense of responsibility towards their patients, ensuring that they stayed in their compound, and that they do not wander off during the journey to the holy water site or clinic. Most attendants reported physically restraining their patients, usually with iron chains. The main rationale for this was the perceived risk of patients escaping, which was thought to be likely because the majority of patients had been brought to the holy water site against their will. It was felt that people with substance use problems were at particularly high risk of escape. "I thought instead of them wandering off all day and night and be attacked by hyenas or going into a ditch I should chain them up" (A4, clinic non-attender) 
1 Some attendants were fearful of being harmed, and in some cases the family requested that their

relative be restrained, either due to fear of violence or to punish them for substance use.

"there is one [patient] who killed a person and served 12 years in prison and then came here. Sometimes he runs away and goes home but his family members leave because they are scared" (A10, clinic attender)

\section{Support to access psychiatric care}

The attendants who had brought patients to the clinic reported keeping the patients' medication for them and ensuring it was taken at the right time.

"I take their medicine from the clinic and make them take it exactly as they should take it. I keep the medication with me for safety and to remind them to take it" (A9, clinic attender)

A minority of attendants reported forcing the patients to take the medication. Attendants also had a gatekeeping role with regards to accessing the clinic, making recommendations to the patients' family on who should attend. Attendants typically brought only one or two of their patients to the clinic, with only one attendant bringing nine patients.

"I try to convince the patient's family about the importance of medical treatment and how the patients could easily recover if they took medical treatment... I explain to them that even if complete healing may not be expected, there will be improvement. They will become at least self-aware" (A14, clinic attender)

\section{Theme 2: Attitudes towards psychiatric treatment}

\section{Positive perspectives towards combining spiritual and psychiatric treatment}

Attitudes towards psychiatric treatment varied. The majority of clinic-attenders related that they are keen to bring patients to the clinic, reporting that medication makes violent and restless patients calmer and sleep better, which makes their job easier. These attendants emphasized that both psychiatric and holy water treatments are a gift from God. Several 
1 attendants believed that holy water treatment and psychiatric treatments complement each

2 other and some reported that both types of treatment were endorsed by the Orthodox

3 Christian Church. Some attendants reported that taking patients to Amanuel Mental Specialized

4 Hospital was challenging if they were restless or violent, and taxi drivers would often refuse to

5 take them. The proximity of the clinic to the holy water site was therefore perceived as a

6 benefit. Some attendants felt that if you are a strong believer, God will help you no matter

7 what type of treatment you seek. These attendants had tended to try holy water treatment

8 initially, only seeking psychiatric treatment if there was no improvement. "I can see real changes when it [medication] is combined with the holy water. It might not work alone but, when it is with the will of God (holy water) it is working very well" (A5, clinic attender)

"We are recommending that both treatments are good for patients. Medical treatments are also part of God's gift. Medicine is an invention of human wisdom that is given by God. Every disease has its own nature. I believe that some diseases need medical treatments. At the same time there are some health problems that are solved only by spiritual treatment. Thus, I believe in the importance of both treatments" (A3, clinic attender)

\section{Negative attitudes towards psychiatric treatment}

In contrast some attendants who had not brought patients to the clinic stated that taking medication is akin to doubting the work of God. It was felt that this would offend God and render the holy water treatment powerless.

\footnotetext{
"Combining both spiritual and medical treatment is not recommended. I know a lot of people who recovered from their illness through spiritual treatment without using medications. I strongly advise patients to be firm in God and take only spiritual treatment." (A7, clinic non-attender)
} 
Impact of training on attitudes

2 Most of the attendants reported that they became aware of the clinic through training delivered

3 by AAU. Training had changed their attitudes towards psychiatric treatment, increased understanding of the importance of medication adherence and potential side effects, and 5 encouraged them to reduce physical restraint and beating.

Theme 3: Decisions about the use of psychiatric treatment

\section{Distinction between spirit possession and mental illness}

12 Attendants tended to make their own judgements about who may or may not benefit from

13 treatment at the clinic. In general, attendants brought patients who they considered to have a 14 mental illness, but not those with substance misuse problems or who they perceived to be 15 possessed by evil spirits. This finding is corroborated by the case note review, which found only $4.2 \%$ of clinic attenders were diagnosed with substance use disorder. Attendants reported being

17 able to easily differentiate between mental illness and spirit possession, mainly through the response to being baptized in the holy water. Attendants reported that those who are possessed by evil spirits often behave normally except during a baptism, when they may scream and shout, try to escape, and speak rapidly about unrelated topics.

"A patient with evil spirits shouts, talks too much and utters irrelevant things when he is baptized. They don't want to hear about and get a treatment of the spiritual type" (A4, clinic non-attender)

\section{6}

In some cases the evil spirit, speaking through the patient, was thought to directly refer to the psychiatric treatment. 
"Sometimes when patients are being baptized the evil spirit might say that "I deliberately rendered the medicine ineffective for the patient" or "I am deliberately making the patient take medication so that I will govern my evil empire" (A10, clinic attender)

The attendants also reported that those who are possessed by evil spirits often went to great lengths to avoid baptism in holy water.

"They will use all their energy to escape from the baptizing area. The energy and force they exert while being baptized is incomparable with the person's energy and character while they are normal" (A12, clinic non-attender)

A few attendants also reported that patients possessed by evil spirits exhibited uncharacteristic behaviour at other times, such as being violent or cruel to animals and people. Finally, spirit possession might also present like a physical illness, such as rendering individuals weak and unable to work or take care of themselves. The prevailing belief was that substance misuse problems, including khat and alcohol misuse, are self-inflicted; a minority of attendants believed that substance misuse arose from spirit possession. It was reported that treatment should therefore involve physical restraint, to reduce access to the substance, as well as spiritual treatment to gain the strength to abstain.

"drug addiction is a manifestation of evil spirit. When he or she is baptized they begin shouting and talking too much. And this is taken as a confirmation of the fact that a drug addict is actually a victim of evil spirits" (A6, clinic non-attender)

\section{Identification of mental illness and use of psychiatric treatment}

The attendants described several behaviours that they associated with mental illness, including talking and laughing alone, collecting garbage, singing songs inappropriately, incoherent speech, muteness, forgetfulness and inability to self care. They also described cases of urinary and faecal incontinence, a lack of awareness of the environment and an absence of meaningful activity. Unlike those thought to have spirit possession, it was reported that those with mental illness would not typically scream during baptism. Whilst for some attendants any evidence of mental illness was sufficient cause to recommend psychiatric treatment, for many violence and sleep 
1 problems were the main impetus. In some cases attendants identified mental illness through a

2 history of previous medical treatment.

3

\section{Role of family members in decisions about source of care}

12 Although attendants were highly influential in determining who accessed the clinic, in many cases

"Those patients, who are a victim of mental disorder talk too much, collecting dirty substances, do not keep their hygiene and try to escape. They also talk and laugh alone. They do not control themselves" (A5, clinic attender)

“When patients don't improve after long time of treatment, don't scream during baptism, collect garbage and speak incoherently then we consider him or her mentally ill" (A4, clinic non-attender)

it was the family members who ultimately made the decision. Resistance from family members was cited as the main reason that some patients are not brought to the clinic by attendants, despite their encouragement. The attendants reported that many families believe that healing can only come from God and that medication will not be helpful. Most families were reportedly also weary of psychiatric treatment; their relatives had often taken it for several years whilst experiencing side effects but no improvement. It was reported that some families found it difficult to accept their loved one had a mental illness. According to some attendants, healing by holy water was more acceptable to the family as well as society.

"The families of the patient are the sole decision makers on whether the patient should attend the clinic or not. Normally, we inform the families of a patient about the clinic. We tell them it is nearby and given for free. However, some families are conservative. They believed that taking medicine will make the patients sedentary. However, we cannot force them. If the family is willing, we [the attendant and the patient] will come to the health service. Most of the challenges come from mothers." (A1, clinic attender) 


\section{Theme 4: Potential service improvements}

2 Some attendants recommended improved availability of anti-psychotic medication at the clinic.

3 Attendants sometimes found there was no free medication in stock, and they were required to

4 purchase it from private pharmacies. This was challenging as they had typically already informed

5 family members that medication would be free of charge. Some attendants also expressed a

6 preference for risperidone as an alternative to chlorpromazine, because of the better side effect 7 profile.

\section{Discussion}

\section{Summary}

24 This exploratory study provides novel insights into how different models of care are viewed and 25 used in the context of a psychiatric-spiritual collaboration in Ethiopia. Overall the qualitative and

"There is inaccessibility of medicine in this clinic. When patients take the red medicine their body shakes and their necks bend. Risperidone is a good medicine for the patients" (A2, clinic attender)

Several attendants asked for more training. Those who had already received AAU training felt they had benefited and would like a refresher, whilst some of those who had not attended voiced a desire for new knowledge.

"Some of the attendants benefited from participating in this training. However, others forgot the points made at the training and hence failed to implement it. I suggest that trainings should be given again to all attendants" (A14, clinic attender)

All of the attendants from St. Michael's site requested a clinic be established near St. Michael's church. For these attendants the one hour journey through the woods to the St Mary Clinic was challenging and there was a perceived risk that patients could abscond. quantitative data suggest the clinic is running successfully. Quantitative findings showed that the majority of patients made several visits and numbers attending have increased over the three 
1 years since it opened. The most common mental disorder amongst clinic attendees was

2 schizophrenia. The vast majority of clinic attendees were resident at the holy water site and over

3 one third had lived there for more than one year. Qualitative data showed that holy water

4 attendants provide daily care for people with mental illness, whilst the only contact with holy

5 water priests is during baptism. Holy water attendants also provide a partial gatekeeping role to

6 psychiatric care, selecting which of their clients they think will benefit and, for these individuals,

7 facilitating attendance to the clinic and anti-psychotic medication adherence. The psychiatric

8 service was felt to be compatible with holy water by some, but not all, holy water attendants.

9 However, family members often had the 'final say' in individuals attending the clinic, in some cases putting up strong resistance to using psychiatric care.

\section{Findings in context}

13 There are few other examples of functioning collaborations between traditional and psychiatric care providers in LMIC. The collaborations that do exist tend to use a 'co-location' model,

15 where different treatment modalities are offered on the same site. Whilst the parallel use of traditional and psychiatric treatments are accepted by psychiatric providers as appropriate, or

17 even desirable, the main direction of referral is often from traditional treatment to psychiatric treatment, rather than vice versa (Green \& Colucci, 2020). This ethos broadly reflects the approach at St Mary's Clinic. As part of a randomized controlled trial (RCT) in Ghana, psychiatrist-led care, comprising psychotropic medication, was offered alongside faith healing at a prayer camp. People with severe mental illness who received the additional psychiatric care experienced reduced symptoms after six weeks compared to those receiving only faith

23 healing (Ofori-Atta et al., 2018). Participants were randomized to intervention arms, and the reasons why eight out of 71 participants randomized to psychiatric care did not receive this

25 intervention were not reported. Comparison with our findings, in terms of understanding the rationale behind accessing different forms of care, is therefore difficult. An informal

27 collaboration in Ghana, in which traditional healers identify potential mental illness in their 28 patients and request psychiatric nurse-led treatment with depot injection, is reportedly 29 acceptable to patients, healers and nurses (Yaro et al., 2020). A further RCT in Nigeria will 
evaluate the effectiveness of primary healthcare providers visiting traditional healing sites to support clinical management of people with psychosis (Gureje et al., 2017). Apparently scarce are truly collaborative care models, in which there are balanced two-way referrals, and fully integrated models in which providers work together in diagnosis, treatment planning or delivery. At the Dawa-Dua ('prayer-treatment') in India, a psychiatric clinic has been established collaboration's successful functioning (Shields et al., 2016).

In our study, in common with accounts from Southern Ethiopia, holy water attendants

12 distinguished between individuals afflicted by spirit possession and mental illness (Alem et al., 13 1999) based on behaviours observed during baptism. Echoing some of the earliest accounts of 14 faith healing in Ethiopia in the scientific literature (Giel et al., 1968), there was consensus that 15 those identified as being possessed should exclusively receive holy water. Only those assessed 16 to have mental illness were felt to gain benefit from psychiatric treatment, and were therefore 17 brought to the clinic. It is difficult to directly map the attendants' classification against 18 psychiatric taxonomy, particularly as baptism behaviours were not witnessed by the 19 investigators. However some behaviours associated with spirit possession (such as rapid 20 irrelevant speech), could conceivably be indicative of a psychotic or dissociative illness. It is 21 generally accepted that hallucinations and delusions associated with schizophrenia are 22 'pathoplastic', meaning that whilst the form is universal, the content is shaped by cultural meanings (Dein, 2017). Conversely, these experiences may not represent any type of mental

24 illness; yet it is noteworthy that these individuals were considered in need of 'treatment' in the 25 form of holy water to the extent their families had left them at the site. Amongst those 26 identified as having mental illness, some attendants felt that both medication and holy water 27 are helpful. A unifying explanatory framework- that both treatments are created by God28 provided a coherent picture of why both treatments could help. Attribution of the success of both spiritual and psychiatric treatment for psychosis to the healing power of God has also 
1 been found amongst religious healers in Uganda (Teuton et al., 2007) and mental healthcare

2 workers in Ghana (Read, 2019).

3 In rural Ethiopia alcohol use disorder is common, particularly amongst street homeless (Ayano

4 et al., 2017; Fekadu et al., 2014), but it is highly stigmatized and rarely treated (Zewdu et al.,

5 2019). Attendants described the increased tendency to physically restrain and restrict food for

6 this group, echoing the association between traumatic experiences, including assault, and

7 comorbid mental illness and substance misuse in rural Ethiopia (Ng et al., 2019). Furthermore,

8 attendants generally perceived substance abuse problems to be unsuitable for psychiatric care

9 and only a small minority of clinic attenders were diagnosed with substance use disorder

10 (4.2\%). For some attendants spirit possession was thought to underlie addiction, meaning

11 spiritual treatment was most appropriate. For others, substance abuse occupied a third

12 category, distinct from either spirit possession or mental illness, and uniquely, was considered

13 to be self-inflicted. These findings may partly reflect Indian research identifying psychosocial

14 factors as common explanatory models for substance use disorders, whilst psychiatric disease

15 models are considered less relevant (Nadkarni et al., 2013). Alternatively, the low numbers

16 attending St Mary's Clinic with such disorders may represent the correct assumption that

17 available treatment for such disorders is limited in this context.

19 Willingness to engage with psychiatric care was mixed amongst attendants. In other settings resistance of healers to collaboration with psychiatric care stems from concerns around loss of

21 business (Morgan et al., 2015), feeling effectiveness is undermined (Gureje et al., 2015) and a

22 mutual sense of distrust (van der Watt et al., 2017). In contrast, the main concern in this study

23 appeared to be around incompatibility of beliefs. This may be because holy water attendants

24 would continue to receive payment, even if both psychiatric treatment and holy water were

25 used, and holy water priests are not paid at all. As holy water attendants are only conduits for

26 using holy water, concerns around being undermined by psychiatric approaches are less

27 relevant. In fact some attendants were highly motivated to use the clinic by potential

28 improvements in their working conditions, such as reduced risk of difficult behaviour. 
1 Aside from their role in baptizing attenders, and in common with previous reports (Giel et al.,

2 1968), holy water priests do not have a therapeutic role with people with mental illness.

3 Furthermore priests and psychiatrists had little say in who receives which services. Instead holy

4 water attendants and family members were most influential. The powerful influence of the

5 family in decision-making about care, and the limited role of people with mental illness in

6 making their own choices, has been noted previously in rural Ethiopia (Souraya et al., 2018). In

7 our study, in common with findings from Ghana and Ethiopia (Hailemariam et al., 2017; Read,

8 2012), family members' treatment preferences were reportedly influenced by pragmatic

9 concerns around medication side effects and inefficacy. At the study site both holy water and

10 psychiatric treatment were free, which may explain why medication concerns were more

11 important than better affordability and payment flexibility, which have been posited as

12 explanations for the popularity of traditional healing in other contexts (Gureje et al., 2015;

13 Kassaye et al., 2006). Similar to reports from Haiti, differing explanatory models amongst

14 service users or their families did not appear to be a primary barrier to using psychiatric care

15 (Khoury et al., 2012). The parallel use of spiritual and psychiatric treatments identified in this

16 study aligns with previous findings from Ethiopia (Alem et al., 1999) (Teferra \& Shibre, 2012),

17 Ghana (Read et al., 2009) and India (Quack, 2013) indicating that help-seeking behavior tends

18 to be shaped by a desire to get well, irrespective of the means by which this is achieved.

20 The large minority of clinic attendees from outside Addis Ababa may indicate that holy water is

21 perceived as an important source of care given that people are willing to travel long distances

22 to access it. The fact the majority had received a formal education, and over a third higher

23 education, may suggest holy water is acceptable and used across the social spectrum (Gureje et

24 al., 2015); however the socio-demographics of clinic attenders may not reflect the wider group

25 of holy water users.

\section{Strengths and limitations}

27 A strength of the qualitative study was the purposive selection of holy water attendants who 28 had never brought people with mental illness to the clinic, as well as those who had. However, 
some participants may have been vulnerable to social desirability bias, therefore overstating their support for the clinic, particularly as the interviewer (XX) was a psychiatrist. Another

3 limitation is the inclusion of only holy water attendants. The views of people with mental

4 illness, family members, psychiatrists and holy water priests, who also have important roles in

5 the way the collaboration functions and is used, remain unknown. A comprehensive review all

6 clinic attendees since its inception was conducted, giving a useful picture of patient socio-

7 demographic and clinical characteristics. However, there were substantial amounts of missing

8 data and validated clinical outcome measures were not used.

\section{Implications}

Overall, this study suggests that implementing a psychiatric clinic in close proximity to a holy

11 water site is a potentially acceptable and feasible way to increase access to evidence-based

12 mental healthcare irrespective of socio-economic status, and particularly for people with

13 schizophrenia. That there is growing demand for St Mary's clinic suggests the needs of people

14 with mental illness are not being entirely met through other mental health services or through

15 holy water treatment. This co-location approach may be applied at other holy water sites in

16 Ethiopia, or adapted for similar traditional or faith healing centres in other countries. Critical

17 success factors may be the careful relationship building prior to initiating the collaboration, the clinic location being a respectful distance from the holy water site, the sensitization and training of holy water priests and attendants and the provision of free antipsychotic medication. Yet whilst there is a shared guiding principle that spiritual and psychiatric treatments may be delivered in parallel, the one-way referral system arguably means that the St Mary's Clinic model cannot be considered truly collaborative. It is possible that more balanced collaboration between the clinic and holy water site could improve engagement by holy water attendants and result in more holistic care for patients. Alternatively, in the context of holy water, a more integrated model may not be practical, necessary or desired by stakeholders, given that nearly all clinic attenders are already using holy water and holy water priests do not have a direct

27 therapeutic role. Future research will explore the appetite for, and practicalities of, more 28 mutual collaboration amongst holy water priests, psychiatrists, attendants and service users. An important finding was the perceived incompatibility of psychiatric and spiritual treatment 
expressed by some attendants. Irrespective of the degree of integration, psychiatrists should be cognisant of the range of explanatory models and the potential importance of spiritual treatment for service users and family members. Future collaborations should continue to be mindful of imposing treatment choices on people with mental illness, attendants, family members and holy water priests.

6 Whilst some attendants who had received the AAU training were less likely to restrain clients 7 who had received psychiatric treatment, other attendants continued to physically restrain their clients. A minority also reported forcing patients to take medication. Collaboration with attendants who are employing harmful practices may present ethical issues for treating psychiatrists (Read, 2019). The ongoing use of restraint may be due to pervasive stigma, fears

11 for safety and the reality that attendants are being paid by, and are accountable to, family 12 members. It is common for people with severe mental illness to be physically restrained in 13 community settings in Ethiopia, often by family members (Asher et al., 2017). Whilst one spiritual- biomedical collaboration in Ghana reportedly resulted in reduced chaining by healers

15 (Yaro et al., 2020), the Ghana RCT found that prayer camp residents continued to be restrained by staff, despite receiving anti-psychotic medication and experiencing symptomatic

17 improvement (Ofori-Atta et al., 2018). These findings suggest that if collaborations with traditional healers are to be effective in addressing human rights abuses, as well as increasing access to evidence-based care, there needs to be a deep understanding of the rationale for existing practices and willingness to consider the concerns and beliefs of all actors (Kpobi \&

22 In this study mainly individuals with disorganized behaviours were identified by attendants as 23 candidates for psychiatric care and the quantitative results show that St Mary's clinic is being used to treat psychotic illness. However, the selection of this group from a wider pool of holy water attenders may account for the lower than expected number of clinic attenders; there 26 were 174 clinic attenders in three years from a resident holy water population of several 27 hundred. In particular, whilst the holy water site may represent a relatively safe space for those with substance use disorder who would otherwise be street homeless, there is a substantial 
unmet need for substance misuse treatment. Moreover, individuals with co-morbid substance use disorder and psychotic illness may be less likely to access treatments for psychosis, which are currently available at the clinic. Training for holy water attendants should clarify the range of presentations, including negative psychotic symptoms, mood symptoms and substance abuse, that may benefit from psychiatric care. The endorsement of psychiatric care by the Orthodox Christian Church, the notion that holy water and medical treatments are both gifts

7 from God and the potential positive impact of psychiatric treatment on working conditions, 8 should also be emphasized in training.

9 It has been suggested that better family and community support for people with mental illness 10 in LMIC might account for the apparently superior clinical accounts in these settings (Cohen et 11 al., 2008). That it is a common practice to leave people with mental illness at holy water sites under the care of attendants, sometimes for years, suggests some family members are not

13 willing or able to act as long term informal caregivers. This is supported by several studies from 14 Ethiopia and other LMIC highlighting the heavy burden on family caregivers including financial 15 burden, stress and stigma (den Hertog \& Gilmoor, 2017; Koschorke et al., 2017; Shibre et al., 2003). This strengthens calls for mental health interventions to focus on increasing the quality

17 of family support (Asher, Fekadu, et al., 2018). An alternative explanation for the long duration of stay is that the strength of the families' faith is such that they are willing to wait long periods 19 for healing to occur (Read et al., 2009). To distinguish between these possibilities further research should involve family members' perspectives.

21 Desirable clinic developments include expanding treatment for substance use disorder, such as 22 motivational interviewing, and improving medication supplies. Psychosocial interventions are 23 likely to be beneficial given the chronic and disabling nature of mental disorders encountered.

24 However, the feasibility of such developments is limited given the low numbers of specialist 25 mental health personnel and potentially unsustainable medication funding. Whilst non26 specialist provision of psychosocial support for psychosis is likely to be acceptable in rural 27 Ethiopia (Asher, Hanlon, et al., 2018), such service developments require funding and 28 supervision infrastructure which are not currently available. Furthermore, attractive models of 
care such as community-based rehabilitation rely on mobilizing family and community networks to promote awareness, to provide support and promote recovery (Kohrt et al., 2018). These approaches may be unfeasible for holy water sites, where residents are living away from their own social networks for long periods. Perhaps more realistic is to consider how the role of holy water attendants can best be developed. There was initial evidence that attendants could support medication adherence, and this could be expanded at St Mary's clinic and replicated elsewhere. The possibility of coercion highlighted in this study has been identified amongst non-specialist providers and family members in previous research in Ethiopia (Souraya et al., 2018) . As Read highlights, with reference to the use of physical restraint by traditional healers, "In promoting collaboration between mental health workers and traditional and faith healers, there is little acknowledgement of the potential irony of transferring persons from one form of coercion to another." (Read, 2019). Training for attendants in how to support medication adherence whilst respecting human rights could include how to discuss the advantages and disadvantages of medication, how to identify and address side effects as well as practical guidance on incorporating medication into daily routines (Asher, Hanlon, et al., 2018).

St Mary's clinic provides free anti-psychotic medication, which is not routinely available in Ethiopia. Difficulties paying for medication and unreliable medication supplies are known to be key barriers to accessing mental healthcare in Ethiopia (Hailemariam et al., 2017). An unintended consequence of free medication provision at a holy water site might be to change patterns of help seeking, such that families may be more likely to send relatives with mental illness to these sites. Living away from family networks for extended periods may impede recovery. Psychiatric -traditional collaborations should be implemented alongside efforts to increase access to mental healthcare in primary care in general, including anti-psychotic medication. In addition provision of psychosocial rehabilitation in service users' own communities may reduce the need for long stays at holy water sites which go beyond a desire for spiritual healing and instead represent an unmet need for long term care. 


\section{Conclusion}

2 The co-location of a psychiatric clinic at a holy water site may increase access to evidence-based

3 care for people with mental illness in Ethiopia. The collaboration is acceptable to some holy

4 water attendants, who provide care for people with mental illness at such sites and act as

5 gatekeepers to psychiatric care. Family members also have a powerful influence on which holy

6 water residents utilise the clinic. The majority of clinic attendees suffer from psychotic

7 disorders. Whilst substance abuse appears to be a common problem amongst holy water

8 residents, and these individuals may be more likely to suffer human rights abuses, the clinic is

9 rarely used for treatment of substance use disorders. The St Mary's Clinic model may be

10 adapted for healing sites elsewhere in Ethiopia and other LMICs. Future clinic developments

11 could include increasing provision of substance misuse treatments and formalising adherence

12 support by attendants. Future research should aim to understand the views of service users,

13 holy water priests and family members in how and why the clinic is used, and how the

14 collaboration can be developed, as well as evaluating clinical and functional improvements

15 amongst clinic attendees. 
Alem, A., Jacobsson, L., Araya, M., Kebede, D., \& Kullgren, G. (1999). How are mental disorders seen and where is help sought in a rural Ethiopian community? A key informant study in Butajira, Ethiopia. Acta Psychiatrica Scandinavica. Supplementum, 397, 40-47.

Asher, L., Fekadu, A., \& Hanlon, C. (2018, Feb 22). Global mental health and schizophrenia. Curr Opin Psychiatry. https://doi.org/10.1097/yco.0000000000000404

Asher, L., Fekadu, A., Teferra, S., De Silva, M., Pathare, S., \& Hanlon, C. (2017, Jul 11). "I cry every day and night, I have my son tied in chains": physical restraint of people with schizophrenia in community settings in Ethiopia. Global Health, 13(1), 47. https://doi.org/10.1186/s12992-017-0273-1

Asher, L., Hanlon, C., Birhane, R., Habtamu, A., Eaton, J., Weiss, H. A., Patel, V., Fekadu, A., \& De Silva, M. (2018, Aug 3). Community-based rehabilitation intervention for people with schizophrenia in Ethiopia (RISE): a 12 month mixed methods pilot study. BMC Psychiatry, 18(1), 250. https://doi.org/10.1186/s12888-018-1818-4

Ayano, G., Assefa, D., Haile, K., Chaka, A., Solomon, H., Hagos, P., Yohannis, Z., Haile, K., Bekana, L., Agidew, M., Demise, S., Tsegaye, B., \& Solomon, M. (2017). Mental, neurologic, and substance use (MNS) disorders among street homeless people in Ethiopia. Ann Gen Psychiatry, 16, 40. https://doi.org/10.1186/s12991-017-0163-1

Bekele, Y. Y., Flisher, A. J., Alem, A., \& Baheretebeb, Y. (2009, Mar). Pathways to psychiatric care in Ethiopia. Psychological Medicine, 39(3), 475-483. https://doi.org/10.1017/s0033291708003929

Braun, V., \& Clarke, V. (2006). Using thematic analysis in psychology. Qualitative Research in Psychology, 3(2), 77-101.

Campbell-Hall, V., Petersen, I., Bhana, A., Mjadu, S., Hosegood, V., \& Flisher, A. J. (2010, Sep). Collaboration between traditional practitioners and primary health care staff in South Africa: developing a workable partnership for community mental health services. Transcult Psychiatry, 47(4), 610-628. https://doi.org/10.1177/1363461510383459 
Cohen, A., Patel, V., Thara, R., \& Gureje, O. (2008, March 1, 2008). Questioning an Axiom: Better Prognosis for Schizophrenia in the Developing World? Schizophrenia Bulletin, 34(2), 229-244. https://doi.org/10.1093/schbul/sbm105

Dein, S. (2017). Recent work on culture and schizophrenia: Epidemiological and anthropological approaches. Global Journal of Archaelogy and Anthropology, 1(3). https://doi.org/DOl: 10.19080/GJAA.2017.01.555562

den Hertog, T. N., \& Gilmoor, A. R. (2017, Mar). Informal care for people with chronic psychotic symptoms: four case studies in a San community in South Africa. Health Soc Care Community, 25(2), 538-547. https://doi.org/10.1111/hsc.12339

Esan, O., Appiah-Poku, J., Othieno, C., Kola, L., Harris, B., Nortje, G., Makanjuola, V., Oladeji, B., Price, L., Seedat, S., \& Gureje, O. (2019, Mar). A survey of traditional and faith healers providing mental health care in three sub-Saharan African countries. Soc Psychiatry Psychiatr Epidemiol, 54(3), 395-403. https://doi.org/10.1007/s00127-018-1630-y

Fekadu, A., Hanlon, C., Gebre-Eyesus, E., Agedew, M., Solomon, H., Teferra, S., Gebre-Eyesus, T., Baheretibeb, Y., Medhin, G., Shibre, T., Workneh, A., Tegegn, T., Ketema, A., Timms, P., Thornicroft, G., \& Prince, M. (2014, Aug 20). Burden of mental disorders and unmet needs among street homeless people in Addis Ababa, Ethiopia. BMC Medicine, 12, 138. https://doi.org/10.1186/s12916-014-0138-x

Fekadu, A., Hanlon, C., Medhin, G., Alem, A., Selamu, M., Giorgis, T. W., Shibre, T., Teferra, S., Tegegn, T., Breuer, E., Patel, V., Tomlinson, M., Thornicroft, G., Prince, M., \& Lund, C. (2015, Oct 7). Development of a scalable mental healthcare plan for a rural district in Ethiopia. British Journal of Psychiatry, 208(Suppl 56), s4-12.

https://doi.org/10.1192/bjp.bp.114.153676

Fekadu, A., Medhin, G., Lund, C., Desilva, M., Selamu, M., Alem, A., Asher, L., Birhane, R., Patel, V., Hailemariam, M., Shibre, T., Thornicroft, G., Prince, M., \& Hanlon, C. (2019, Oct 29). The psychosis treatment gap and its consequences in rural Ethiopia. BMC Psychiatry, 19(1), 325. https://doi.org/10.1186/s12888-019-2281-6

Giel, R., Gezahegn, Y., \& van Luijk, J. N. (1968, Mar). Faith-healing and spirit-possession in Ghion, Ethiopia. Social Science and Medicine, 2(1), 63-79. 
Girma, E., Tesfaye, M., Froeschl, G., Moller-Leimkuhler, A. M., Muller, N., \& Dehning, S. (2013). Public stigma against people with mental illness in the Gilgel Gibe Field Research Center (GGFRC) in Southwest Ethiopia. PloS One, 8(12), e82116. https://doi.org/10.1371/journal.pone.0082116

Green, B., \& Colucci, E. (2020, Feb). Traditional healers' and biomedical practitioners' perceptions of collaborative mental healthcare in low- and middle-income countries: A systematic review. Transcult Psychiatry, 57(1), 94-107.

https://doi.org/10.1177/1363461519894396

Gureje, O., Makanjuola, V., Kola, L., Yusuf, B., Price, L., Esan, O., Oladeji, B. D., Appiah-Poku, J., Haris, B., Othieno, C., \& Seedat, S. (2017, Oct 10). COllaborative Shared care to IMprove Psychosis Outcome (COSIMPO): study protocol for a randomized controlled trial. Trials, 18(1), 462. https://doi.org/10.1186/s13063-017-2187-x

Gureje, O., Nortje, G., Makanjuola, V., Oladeji, B. D., Seedat, S., \& Jenkins, R. (2015, Feb). The role of global traditional and complementary systems of medicine in the treatment of mental health disorders. Lancet Psychiatry, 2(2), 168-177. https://doi.org/10.1016/s2215-0366(15)00013-9

Hailemariam, M., Fekadu, A., Prince, M., \& Hanlon, C. (2017, Aug 29). Engaging and staying engaged: a phenomenological study of barriers to equitable access to mental healthcare for people with severe mental disorders in a rural African setting. Int J Equity Health, 16(1), 156. https://doi.org/10.1186/s12939-017-0657-0

James, B. O., Igbinomwanhia, N. G., \& Omoaregba, J. O. (2014, Aug). Clergy as collaborators in the delivery of mental health care: an exploratory survey from Benin City, Nigeria. Transcult Psychiatry, 51(4), 569-580. https://doi.org/10.1177/1363461514525219

Kahana, Y. (1985, Summer). The Zar spirits, a category of magic in the system of mental health care in Ethiopia. International Journal of Social Psychiatry, 31(2), 125-143.

Kassaye, K. D., Amberbir, A., Getachew, B., \& Mussema, Y. (2006). A historical overview of traditional medicine policy in Ethiopia. Ethiopian Journal of Health Development, 20(2), 127- 134.

Khoury, N. M., Kaiser, B. N., Keys, H. M., Brewster, A. R., \& Kohrt, B. A. (2012, Sep). Explanatory models and mental health treatment: is vodou an obstacle to psychiatric treatment in 
rural Haiti? Culture, Medicine and Psychiatry, 36(3), 514-534.

https://doi.org/10.1007/s11013-012-9270-2

Kohrt, B. A., Asher, L., Bhardwaj, A., Fazel, M., Jordans, M. J. D., Mutamba, B. B., Nadkarni, A., Pedersen, G. A., Singla, D. R., \& Patel, V. (2018, Jun 16). The Role of Communities in Mental Health Care in Low- and Middle-Income Countries: A Meta-Review of Components and Competencies. International Journal of Environmental Research and Public Health, 15(6). https://doi.org/10.3390/ijerph15061279

Kortmann, F. (1987). Popular, Traditional and Professional Mental Health Care in Ethiopia. Transcultural Psychiatric Research Review, 24.

Koschorke, M., Padmavati, R., Kumar, S., Cohen, A., Weiss, H. A., Chatterjee, S., Pereira, J., Naik, S., John, S., Dabholkar, H., Balaji, M., Chavan, A., Varghese, M., Thara, R., Patel, V., \& Thornicroft, G. (2017, Apr). Experiences of stigma and discrimination faced by family caregivers of people with schizophrenia in India. Social Science and Medicine, 178, 6677. https://doi.org/10.1016/i.socscimed.2017.01.061

Kpobi, L., \& Swartz, L. (2019, Jul 22). Indigenous and faith healing in Ghana: A brief examination of the formalising process and collaborative efforts with the biomedical health system. Afr J Prim Health Care Fam Med, 11(1), e1-e5. https://doi.org/10.4102/phcfm.v11i1.2035

Mercier, J. (1997). Art that Heals: Image as Medicine in Ethiopia. Prestel.

Morgan, C., Hibben, M., Esan, O., John, S., Patel, V., Weiss, H. A., Murray, R. M., Hutchinson, G., Gureje, O., Thara, R., \& Cohen, A. (2015, Jun). Searching for psychosis: INTREPID (1): systems for detecting untreated and first-episode cases of psychosis in diverse settings. Social Psychiatry and Psychiatric Epidemiology, 50(6), 879-893. https://doi.org/10.1007/s00127-015-1013-6

Mulatu, M. S. (1999, Jul). Perceptions of Mental and Physical Illnesses in North-western Ethiopia: Causes, Treatments, and Attitudes. Journal of Health Psychology, 4(4), 531549. https://doi.org/10.1177/135910539900400407

Musyimi, C. W., Mutiso, V. N., Nandoya, E. S., \& Ndetei, D. M. (2016). Forming a joint dialogue among faith healers, traditional healers and formal health workers in mental health in a 
Kenyan setting: towards common grounds. J Ethnobiol Ethnomed, 12(1), 4. https://doi.org/10.1186/s13002-015-0075-6

Nadkarni, A., Dabholkar, H., McCambridge, J., Bhat, B., Kumar, S., Mohanraj, R., Murthy, P., \& Patel, V. (2013, Dec). The explanatory models and coping strategies for alcohol use disorders: an exploratory qualitative study from India. Asian Journal of Psychiatry, 6(6), 521-527. https://doi.org/10.1016/i.ajp.2013.06.010

National Mental Health Strategy 2012-2015. (2012).

Ng, L. C., Medhin, G., Hanlon, C., \& Fekadu, A. (2019, Feb 20). Trauma exposure, depression, suicidal ideation, and alcohol use in people with severe mental disorder in Ethiopia. Social Psychiatry and Psychiatric Epidemiology. https://doi.org/10.1007/s00127-019$\underline{01673-2}$

Ofori-Atta, A., Attafuah, J., Jack, H., Baning, F., \& Rosenheck, R. (2018, Jan). Joining psychiatric care and faith healing in a prayer camp in Ghana: randomised trial. British Journal of Psychiatry, 212(1), 34-41. https://doi.org/10.1192/bip.2017.12

Patel, V. (2015, Aug 5). Universal Health Coverage for Schizophrenia: A Global Mental Health Priority. Schizophrenia Bulletin, 42(4), 885-890. https://doi.org/10.1093/schbul/sbv107

Quack, J. (2013, 2013/04/01). “What do I know?” Scholastic fallacies and pragmatic religiosity in mental health-seeking behaviour in India. Mental Health, Religion \& Culture, 16(4), 403418. https://doi.org/10.1080/13674676.2012.679358

Read, U. (2012, Jul). "I want the one that will heal me completely so it won't come back again": the limits of antipsychotic medication in rural Ghana. Transcult Psychiatry, 49(3-4), 438460. https://doi.org/10.1177/1363461512447070

Read, U. M. (2019, Dec). Rights as Relationships: Collaborating with Faith Healers in Community Mental Health in Ghana. Cult Med Psychiatry, 43(4), 613-635. https://doi.org/10.1007/s11013-019-09648-3

Read, U. M., Adiibokah, E., \& Nyame, S. (2009). Local suffering and the global discourse of mental health and human rights: an ethnographic study of responses to mental illness in rural Ghana. Global Health, 5, 13. https://doi.org/10.1186/1744-8603-5-13 
Selamu, M., Asher, L., Hanlon, C., Medhin, G., Hailemariam, M., Patel, V., Thornicroft, G., \& Fekadu, A. (2015). Beyond the biomedical: community resources for mental health care in rural ethiopia. PloS One, 10(5), e0126666. https://doi.org/10.1371/journal.pone.0126666

Shibre, T., Kebede, D., Alem, A., Negash, A., Deyassa, N., Fekadu, A., Fekadu, D., Jacobsson, L., \& Kullgren, G. (2003, Jan). Schizophrenia: illness impact on family members in a traditional society--rural Ethiopia. Social Psychiatry and Psychiatric Epidemiology, 38(1), 27-34.

Shibre, T., Teferra, S., Morgan, C., \& Alem, A. (2010, Jun). Exploring the apparent absence of psychosis amongst the Borana pastoralist community of Southern Ethiopia. A mixed method follow-up study. World Psychiatry, 9(2), 98-102.

Shields, L., Chauhan, A., Bakre, R., Hamlai, M., Lynch, D., \& Bunders, J. (2016, Jun). How can mental health and faith-based practitioners work together? A case study of collaborative mental health in Gujarat, India. Transcult Psychiatry, 53(3), 368-391. https://doi.org/10.1177/1363461516649835

Solera-Deuchar, L., Mussa, M. I., Ali, S. A., Haji, H. J., \& McGovern, P. (2020). Establishing views of traditional healers and biomedical practitioners on collaboration in mental health care in Zanzibar: a qualitative pilot study. Int J Ment Health Syst, 14, 1. https://doi.org/10.1186/s13033-020-0336-1

Souraya, S., Hanlon, C., \& Asher, L. (2018, Aug 22). Involvement of people with schizophrenia in decision-making in rural Ethiopia: a qualitative study. Global Health, 14(1), 85. https://doi.org/10.1186/s12992-018-0403-4

Teferra, S., \& Shibre, T. (2012). Perceived causes of severe mental disturbance and preferred interventions by the Borana semi-nomadic population in southern Ethiopia: a qualitative study. BMC Psychiatry, 12(1), 79. http://www.biomedcentral.com/1471-244X/12/79

Teuton, J., Dowrick, C., \& Bentall, R. P. (2007, Sep). How healers manage the pluralistic healing context: the perspective of indigenous, religious and allopathic healers in relation to psychosis in Uganda. Social Science and Medicine, 65(6), 1260-1273. https://doi.org/10.1016/i.socscimed.2007.03.055 
Torrey, E. F. (1967, Summer). The Zar Cult in Ethiopia. International Journal of Social Psychiatry, 13(3), 216-223.

van der Watt, A. S. J., Nortje, G., Kola, L., Appiah-Poku, J., Othieno, C., Harris, B., Oladeji, B. D., Esan, O., Makanjuola, V., Price, L. N., Seedat, S., \& Gureje, O. (2017, Dec). Collaboration Between Biomedical and Complementary and Alternative Care Providers: Barriers and Pathways. Qual Health Res, 27(14), 2177-2188. https://doi.org/10.1177/1049732317729342

Vecchiato, N. L. (1993). Traditional medicine. In H. Kloos \& Z. A. Zein (Eds.), The Ecology of Health and Disease in Ethiopia. Westview Press.

Yaro, P. B., Asampong, E., Tabong, P. T., Anaba, S. A., Azuure, S. S., Dokurugu, A. Y., \& Nantogmah, F. A. (2020, May 5). Stakeholders' perspectives about the impact of training and sensitization of traditional and spiritual healers on mental health and illness: $A$ qualitative evaluation in Ghana. Int J Soc Psychiatry, 20764020918284. https://doi.org/10.1177/0020764020918284

Zewdu, S., Hanlon, C., Fekadu, A., Medhin, G., \& Teferra, S. (2019, Jan 18). Treatment gap, helpseeking, stigma and magnitude of alcohol use disorder in rural Ethiopia. Subst Abuse Treat Prev Policy, 14(1), 4. https://doi.org/10.1186/s13011-019-0192-7 
Table 1 Clinic attendance by year

\begin{tabular}{|l|l|l|}
\hline Year & $\begin{array}{l}\text { Total patients seen in } \\
\text { clinic* }\end{array}$ & $\begin{array}{l}\text { Mean number patients per } \\
\text { clinic session }\end{array}$ \\
\hline 2012 & 124 & 7 \\
\hline 2013 & 309 & 17 \\
\hline 2014 (to end of July) & 551 & 25 \\
\hline
\end{tabular}

* Patients may be seen on more than one occasion

Table 2 Sociodemographic characteristics of clinic attendees

\begin{tabular}{|c|c|c|}
\hline Variable & $\mathbf{N}$ & $\%$ \\
\hline \multicolumn{3}{|l|}{ Sex } \\
\hline Male & 138 & 79.3 \\
\hline Female & 36 & 20.7 \\
\hline \multicolumn{3}{|l|}{ Age (years) } \\
\hline$<20$ & 6 & 3.7 \\
\hline 20- 39 & 124 & 76.5 \\
\hline $40-60$ & 32 & 19.8 \\
\hline Missing & 12 & \\
\hline \multicolumn{3}{|c|}{ Usual residence } \\
\hline Addis Ababa & 58 & 61.7 \\
\hline Out of Addis & 36 & 38.8 \\
\hline Missing & 80 & \\
\hline \multicolumn{3}{|l|}{ Religion } \\
\hline Orthodox & 72 & 87.8 \\
\hline Muslim & 4 & 4.9 \\
\hline Protestant & 6 & 7.3 \\
\hline Missing & 92 & \\
\hline \multicolumn{3}{|c|}{ Any formal education } \\
\hline Yes & 86 & 89.6 \\
\hline No & 10 & 10.4 \\
\hline Missing & 78 & \\
\hline
\end{tabular}




\begin{tabular}{|l|l|l|}
\hline Level of education & & \\
\hline Elementary school & 22 & 26.2 \\
\hline High school & 32 & 38.1 \\
\hline Higher education & 30 & 35.7 \\
\hline Missing & 90 & \\
\hline
\end{tabular}

Table 3 Pattern of holy water use amongst clinic attendees

\begin{tabular}{|c|c|c|}
\hline Variable & $\mathbf{N}$ & $\%$ \\
\hline \multicolumn{3}{|c|}{ Holy water site attended } \\
\hline St. Michael & 62 & 86.1 \\
\hline St. Mary & 10 & 13.9 \\
\hline Missing & 102 & \\
\hline \multicolumn{3}{|c|}{ Who accompanies attendee to the clinic } \\
\hline Holy water attendant & 76 & 65.5 \\
\hline Family & 32 & 27.6 \\
\hline Both & 8 & 6.9 \\
\hline Missing & 58 & \\
\hline \multicolumn{3}{|c|}{ Living at the holy water site } \\
\hline Yes & 118 & 96.7 \\
\hline No & 4 & 3.3 \\
\hline Missing & 52 & \\
\hline \multicolumn{3}{|c|}{ Duration of stay at holy water site } \\
\hline$<1$ year & 48 & 48 \\
\hline $1-5$ years & 22 & 22 \\
\hline$>5$ years & 16 & 16 \\
\hline Missing & 74 & \\
\hline
\end{tabular}


Table 4 Diagnosis, outcome and medication adherence amongst clinic attendees

\begin{tabular}{|c|c|c|}
\hline Variable & $\mathbf{N}$ & $\%$ \\
\hline \multicolumn{3}{|l|}{ Diagnosis } \\
\hline Schizophrenia & 121 & 73.3 \\
\hline Schizoaffective disorder & 12 & 7.3 \\
\hline Bipolar disorder with psychotic features & 14 & 8.5 \\
\hline Substance use disorder & 7 & 4.2 \\
\hline Major depressive disorder & 8 & 4.8 \\
\hline Seizure disorder & 1 & 0.6 \\
\hline Mild mental retardation with behavioural disturbance & 1 & 0.6 \\
\hline Mental retardation +cerebral palsy+ seizure disorder & 1 & 0.6 \\
\hline Missing & 9 & \\
\hline \multicolumn{3}{|l|}{ Previous medical treatment } \\
\hline Yes, at Amanuel Specialized Mental Hospital & 46 & 48.4 \\
\hline Yes, at other unspecified location & 12 & 12.6 \\
\hline None & 37 & 38.9 \\
\hline Missing & 79 & \\
\hline \multicolumn{3}{|l|}{ Total number visits to clinic } \\
\hline 1 & 4 & 3.8 \\
\hline 2 & 12 & 11.5 \\
\hline 3 & 6 & 5.8 \\
\hline 4 & 82 & 78.8 \\
\hline Missing & 70 & \\
\hline \multicolumn{3}{|l|}{ Symptom improvement since first clinic attendance } \\
\hline No improvement & 12 & 12 \\
\hline Some improvement & 76 & 76 \\
\hline Full improvement & 12 & 12 \\
\hline Missing & 74 & \\
\hline \multicolumn{3}{|l|}{ Anti-psychotic medication adherence } \\
\hline Takes medication some days & 24 & 25.5 \\
\hline Takes medication every day & 70 & 74.5 \\
\hline
\end{tabular}




\begin{tabular}{|l|l|l|}
\hline Missing & 80 & \\
\hline Lost to follow up after first clinic attendance & & \\
\hline Yes & 42 & 24.1 \\
\hline No & 132 & 75.9 \\
\hline Missing & 0 & \\
\hline
\end{tabular}

